\title{
||||||||||||||||||||||||||||||||||||||||||||||||||||||||||||||||||||||.
}

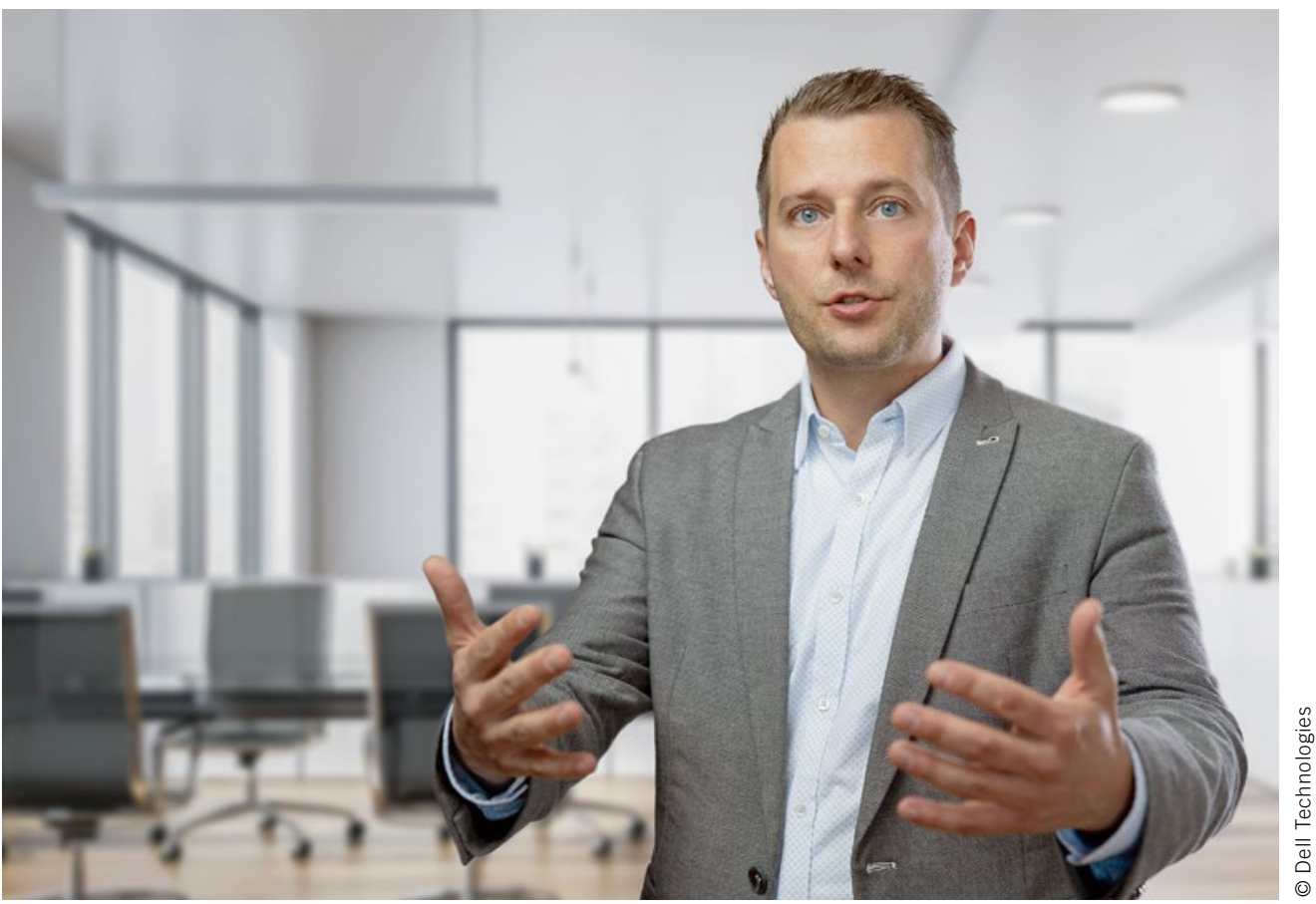

Dr. Florian Baumann

CTO Automotive und Artificial

Intelligence bei Dell Technologies

\section{Der Rohstoff für die Mobilität von morgen sind Daten}

Wie bringt man ein autonomes Fahrzeug dazu, sich an die Straßenverkehrsordnung zu halten? Es muss lernen, lernen und noch einmal lernen. Grundlage dafür sind hochkomplexe On-BoardTechnologien wie Fahrassistenzsysteme, die mithilfe von Sensoren dem Fahrzeug jederzeit eine $360^{\circ}$-Ansicht auf die Straßenund Verkehrssituation ermöglichen. Lidar, Kameras und Radar verleihen dem autonomen Fahrzeug das Sehvermögen - aber erst die intelligente Verknüpfung aller Daten und eine entsprechende Software-Algorithmik machen es möglich, dass das Auto selbstständige Entscheidungen trifft.

Design, Entwicklung und Tests dieser Fahrassistenzsysteme sind sehr komplex: Die Automobilhersteller müssen dazu viele verschiedene Verkehrsszenarien abbilden. Das reicht von Straßen- und Umgebungsgeometrie, dem Verhalten von Fahrern und Fußgängern über unterschiedliche Verkehrs- und Wetterbedingungen bis hin zu Wechselwirkungen zwischen einzelnen Sensoren oder dem Ausfall von ganzen Komponenten. Je höher der Automatisierungsgrad ist, desto mehr Daten muss die Automobilindustrie mit ihren Testfahrzeugen erfassen. Der SAE-Level 3 erfordert typischerweise eine Million real gefahrene Kilometer, um ausreichende Bedingungen für die Softwareentwicklung und -validierung zu simulieren. Die Automatisierung der Stufe 5, dem völlig autonomen Fahren, setzt bereits rund 240 Millionen km voraus. Schon ein Projekt auf Level 3 erfasst bei der vorgegebenen Fahrleistung etwa 19,3 Petabyte Rohdaten. Bei Level 5 sind wir bereits im Exabyte-Bereich. Diese massive Datenübertragung zwischen dem fahrzeugseitigen System und der zentralen IT führt bei klassischen Ansätzen zwangsläufig zu einer Überlastung von Infrastruktur und Datenverwaltungssystemen. Die Rechenkomplexität steigt dabei ins Unermessliche.

Ohne echte Intelligenz und eine vollintegrierte Entwicklungsplattform lässt sich das Problem nicht lösen. Eine solche Plattform stellt automatisierte Prozesse und Workflows bereit, um Datensätze bereits beim Kopiervorgang vom Fahrzeug in die eigene Infrastruktur in Echtzeit auf Relevanz untersuchen zu können. Im Anschluss werden Datenstrukturen im eigenen Rechenzentrum unter Zuhilfenahme von speziellen Algorithmen vorverarbeitet und komprimiert. Dadurch wird eine kosteneffizientere Speicherung ermöglicht und sichergestellt. Eine Echtzeitverarbeitung von Daten vom Fahrzeug in die eigene Cloud und von der eigenen Cloud zum Fahrzeug setzt zudem jederzeit eine geringe Latenz voraus.

Autonomes Fahren ist ohne Big Data, künstliche Intelligenz und 5G nicht möglich: Die Frage der Erfassung, der Speicherung und der Verwaltung aller Daten ist Dreh- und Angelpunkt einer zuverlässigen vernetzten Mobilität. 